\title{
ENHANCEMENT BY UBENIMEX (BESTATIN) OF HOST RESISTANCE TO Candida albicans INFECTION
}

\author{
Kayo Aoyagi, Noriko Itoh, Fuminori Abe, Shigeru Abe ${ }^{\dagger}$, \\ KatsuHISA UCHIDA $^{\dagger \dagger}$, MasaAKI IshIZUKa ${ }^{\dagger \dagger}$, TOMIO TaKeUCHI ${ }^{\dagger \dagger}$ \\ and HideYo Yamaguchi ${ }^{\dagger}$ \\ Research Laboratories, Pharmaceuticals Group, \\ Nippon Kayaku Co., Ltd., \\ 3-31-12 Shimo, Kita-ku, Tokyo 115, Japan \\ ${ }^{\dagger}$ Teikyo University School of Medicine, \\ 2-11-1 Kaga, Itabashi-ku, Tokyo 173, Japan \\ ${ }^{\dagger \dagger}$ Teikyo University Research Center for Medical Mycology, \\ 359 Ohtsuka, Hachiohji-shi, Tokyo 192, Japan \\ ${ }^{\dagger \dagger \dagger}$ Institute of Microbial Chemistry, \\ 3-14-23 Kamiosaki, Shinagawa-ku, Tokyo 141, Japan
}

(Received for publication June 8, 1992)

\begin{abstract}
Ubenimex is a low molecular weight microbial metabolite which has been demonstrated to have antifumor and immunomodulatory activities. In this study, the protective effect of ubenimex on Candida albicans infection was investigated in normal and immunosuppressed mice. In normal mice, treatment with ubenimex at $0.5,5$ and $25 \mathrm{mg} / \mathrm{kg}$ for 5 days prior to infection prolonged survival time in a dose-dependent manner. In immunosuppressed mice treated with a single dose of cyclophosphamide 4 days prior to infection, ubenimex treatment at $5 \mathrm{mg} / \mathrm{kg}$ for 5 days significantly increased the number of survivors. Ubenimex-treated mice had a significant increase in number of peritoneal exudate cells with neutrophils as well as enhanced functions, including phagocytosis and active oxygen production. These results suggest the potential usefulness of ubenimex as a prophylactic agent for the management of patients with opportunistic fungal infections.
\end{abstract}

Ubenimex was found by UMEZAWA et al to be an inhibitor of aminopeptidases in culture filtrates of Streptomyces olivoreticuli ${ }^{1)}$ and it can be chemically synthesized. We have undertaken a variety of immunopharmacological studies on ubenimex and demonstrated that it stimulates macrophages, $T$ cells and bone marrow cells and has antitumor activity ${ }^{2,3)}$. It would be seem, therefore, that ubenimex enhances the production and/or induction of various cytokines from immunocompetent cells and modulates the function of antitumor effectors such as macrophages, cytotoxic $T$ cells and natural killer (NK) cells. Since ubenimex is a substance with low molecular weight, its pharmacological behavior has been examined in detail ${ }^{4}$. An autoradiographic study of tissue distribution of $\left[{ }^{3} \mathrm{H}\right]$-ubenimex demonstrated that it is efficiently distributed in macrophages in lymphoid tissues and solid tumors in mice ${ }^{5)}$. Biochemical and histochemical studies proved that one of the binding sites for ubenimex is aminopeptidase $\mathrm{N}$ (EC 3.4.11.12) which is located on the surface of mammalian cells ${ }^{6}$. It is well absorbed by oral administration, extremely low in toxicity and can be safely administered over a long period to humans. The efficacy and toxicity of ubenimex in humans has been evaluated by many researchers in well-controlled clinical trials ${ }^{3)}$. OTA et al. demonstrated that ubenimex prolongs the duration of remission and survival time in adult non-lymphocytic leukemia patients who achieved a complete remission by induction and consolidation chemotherapy ${ }^{7}$. It was also observed through these clinical studies that ubenimex might be effective in protecting immunodeficient patients from opportunistic infections. 
There are several papers on preclinical studies of ubenimex with experimental infections. Harada et al. reported that ubenimex enhanced host resistance to Listeria monocytogenes infection in mice ${ }^{8)}$. DICKNITE et al. demonstrated that it reduced bacterial persistence in experimental chronic Salmonella typhimurium infection in mice9), and TANAKA et al. observed that it has a prophylactic effect on experimental pyelonephritis induced by Pseudomonas aeruginosa ${ }^{10)}$. In viral infections, ubenimex enhanced production of antibody to Herpes simplex in mice ${ }^{11)}$ and increased the number of $\mathrm{CD} 4^{+}$lymphocytes in acquired immunodificiency syndrome (AIDS) and AIDS-related complex patients ${ }^{12}$. Considering these biological response modifier (BRM) characteristics and the beneficial effect on bacterial and viral infections, ubenimex was expected to be effective against fungal infections. We therefore examined its effects on experimental Candida albicans infection in mice and we report here prevention of this infection and activation of murine neutrophils in vivo.

\section{Materials and Methods}

\section{Animals}

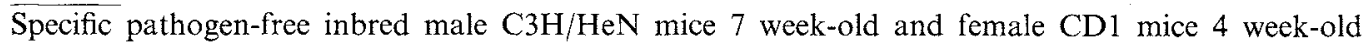
were obtained from Charles River Japan, Inc., Atsugi, Kanagawa. Mice were housed at a temperature of $25 \pm 2{ }^{\circ} \mathrm{C}$ and a humidity of $55 \pm 7 \%$, and fed standard mouse diet (NMFR, Oriental Yeast Co., Ltd., Tokyo) and water ad libitum.

\section{Fungi}

C. albicans TIMM 0239 and 1768 were maintained at the Research Center for Medical Mycology, Teikyo University. Fungi were grown in Sabouraud Dextrose broth containing $0.5 \%$ yeast extract overnight at $37^{\circ} \mathrm{C}$ in a shaking water bath. Cultures were then centrifuged for 5 minutes at $1,500 \mathrm{rpm}$ and resulting C. albicans cells washed five times with physiological saline. The number of C. albicans cells was counted with a hemocytometer.

\section{Agents}

Ubenimex was prepared by Nippon Kayaku Co., Ltd., Tokyo. It was dissolved in physiological saline and filtered through a Millipore filter $(0.22 \mu \mathrm{m})$. Limulus hemocyto lysate assay (E-toxate, Sigma Chemical Co., St. Louis, MO) detected no endotoxin. Cyclophosphamide was purchased from Shionogi Co., Ltd., Osaka, and dissolved in distilled water before use. OK-432 was a gift from Chugai Co., Ltd., Tokyo. Luminol solution was purchased from Nichi-on Co., Ltd., Chiba.

\section{Systemic Infection of Mice}

Normal mice were intravenously (iv) infected with $1 \times 10^{6}$ cells of C. albicans TIMM 1768 . Immunosuppressed mice produced by intraperitoneal treatment with a single dose of $200 \mathrm{mg} / \mathrm{kg}$ of cyclophosphamide 4 days prior to infection were iv infected with $5 \times 10^{4}$ cells of C. albicans. Ubenimex was intraperitoneally (ip) administered daily for the 5 consecutive days preceding the infection.

\section{Detection of C. albicans in Kidneys}

At the end of the experimental period surviving mice were sacrificed, and kidneys dissected under sterile conditions. The vertically cut face of each kidney was pressed against the surface of Candida GS agar $(1 \%$ peptone, $0.5 \%$ yeast extract, $4 \%$ glucose, $2 \%$ agar and $0.05 \%$ 5-nitro-2-furfurylidineaminoguanide hydrochloride) plates that were then incubated for 48 hours at $37^{\circ} \mathrm{C}$ to observe colonial growth of $C$. albicans. 
administration, each mouse ip received an injection of $2 \mathrm{ml}$ of $8 \%$ casein sodium. Six hours later the PEC were obtained with $5 \mathrm{ml} /$ mouse of DULBECCo's phosphate buffered saline (PBS).

Preparation of Murine Neutrophils

Purification of neutrophils was performed as described by MORIKAWA et al. ${ }^{13)}$. Briefly, PEC were obtained as described above and resuspended in PBS after 5 minutes centrifugation at $1,500 \mathrm{rpm}$. The suspension was layered gently on $90 \%$ Ficoll-paque, and centrifuged for 30 minutes at 1,700 rpm. The sedimented cells in the tube were recovered and confirmed to consist of more than $95 \%$ neutrophils by microscopical estimation using Diff-quik (Green Cross Co., Ltd., Osaka) staining.

\section{Phagocytosis of C. albicans Cells by Neutrophils}

Murine neutrophils in PEC following ubenimex treatment were suspended in RPMI-1640 medium containing $10 \%$ fetal calf serum at a concentration of $4 \times 10^{6} \mathrm{cells} / \mathrm{ml}$. Formalin-killed $C$. albicans TIMM 0239 cells were also suspended in the same medium at $2 \times 10^{7} \mathrm{cells} / \mathrm{ml}$. The neutrophil suspension $(500 \mu \mathrm{l})$, formalin-killed C. albicans cell suspension $(500 \mu \mathrm{l})$, and normal mouse serum $(50 \mu \mathrm{l})$ were mixed together in a centrifuge tube, and incubated for 30 minutes at $37^{\circ} \mathrm{C}$. Aliquots of the incubation mixture $(50 \mu \mathrm{l})$ were then stained with an equal volume of $0.4 \%$ trypan blue and $0.2 \%$ eosin $\mathrm{Y}$ in $\mathrm{PBS}^{14)}$. Phagocytic activity was determined by measuring the total number of phagocytized C. albicans cells in 200 neutrophils.

\section{Chemiluminescence Response}

The chemiluminescence response of the neutrophils was measured as described by ALLEN et al. ${ }^{15)}$. Briefly, neutrophils were suspended in $10 \mathrm{~mm}$ HEPES buffer (pH 7.4) containing $5 \mathrm{~mm} \mathrm{KCl}, 145 \mathrm{~mm} \mathrm{NaCl}$, $5.5 \mathrm{~mm}$ glucose and $1 \mathrm{mM} \mathrm{CaCl}_{2}$ at a concentration of $3 \times 10^{6} \mathrm{cells} / \mathrm{ml}$ just prior to measurement. Twenty-five $\mu \mathrm{l}$ of $10 \mathrm{KE} / \mathrm{ml}$ of OK432 was added to $100 \mu \mathrm{l}$ of the neutrophil suspension, and the mixture preincubated for one minute at $37^{\circ} \mathrm{C}$. Then $100 \mu \mathrm{l}$ of $2 \times 10^{-4} \mathrm{M}$ luminol solution was added with a microsyringe, and chemiluminescence was measured by Picolite (Model 6100 PICO-LITE, Packard, Tokyo)

\section{Statistics}

Statistical analysis was carried out by Fisher exact test or STUdent's $t$-test.

\section{Results}

\section{Prophylactic Effect of Ubenimex on C. albicans Infection in Normal Mice}

The prophylactic effect on $C$. albicans infection was first examined in normal CD1 mice which were iv infected with $1 \times 10^{6}$ cells of $C$. albicans. All saline-treated mice died within 6 days after being infected. Treatment with 5 daily doses of ubenimex at $0.5,5$ or $25 \mathrm{mg} / \mathrm{kg}$, however, prolonged the survival time in a dose-dependent manner as shown in Fig. 1, the most effective dose being $25 \mathrm{mg} / \mathrm{kg}$.

Prophylactic Effect of Ubenimex on C. albicans Infection in Immunosuppressed Mice

Table 1 shows the results of experiments in which the prophylactic effect on C. albicans was examined in cyclophosphamide-induced immunosuppressed mice. The immunosuppressed mice died within 14 days following infection with $5 \times 10^{4}$ cells of $C$. albicans. Other mice were given ubenimex daily for 5 days prior to the infection and this treatment prolonged survival time; the number of animals surviving more than 14 days was: 4 out of 7 mice at $0.5 \mathrm{mg} / \mathrm{kg}$, 4 out of 6 at $5 \mathrm{mg} / \mathrm{kg}$ and 1 out of 7 at $25 \mathrm{mg} / \mathrm{kg}$. The surviving animals were then sacrificed and examined to determine whether $C$. albicans cells were still present in the kidneys. Two out of 4 mice at $0.5 \mathrm{mg} / \mathrm{kg}$ and 1 out of 4 at $5 \mathrm{mg} / \mathrm{kg}$ of ubenimex showed no detectable C. albicans in some kidney-stamps when examined 14 days after infection. This suggested that ubenimex was more effective against $C$. albicans infection in immunosuppressed mice than in normal mice at $5 \mathrm{mg} / \mathrm{kg}$, but did not completely eliminate $C$. albicans. 
Fig. 1. Prophylactic effect of ubenimex on Candida albicans infection in normal mice. day -1 .

Ubenimex $0.5 \mathrm{mg} / \mathrm{kg}(\mathbf{\Delta}), 5 \mathrm{mg} / \mathrm{kg}(\mathbf{G}), 25 \mathrm{mg} / \mathrm{kg}(\bullet)$ or saline (O) was administered on day -5 to

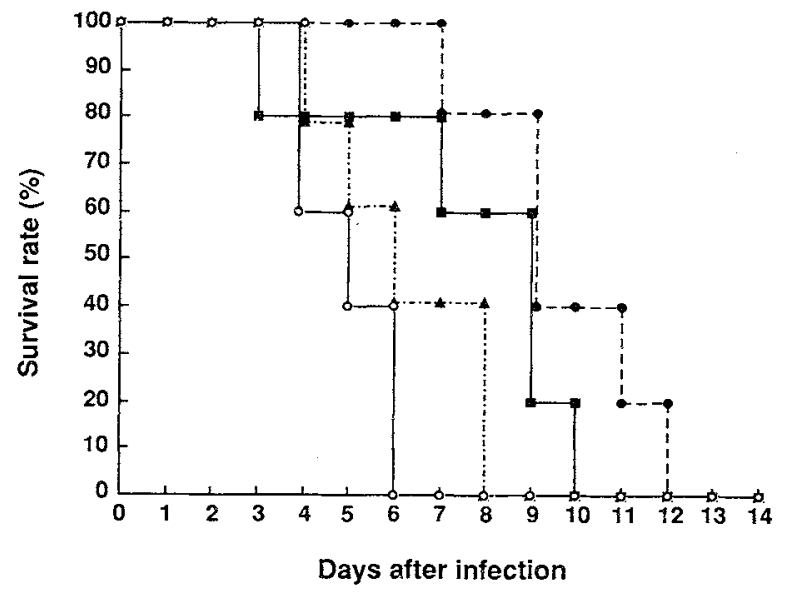

Female CD1 mice ( 4 weeks, 5 animals/dose) were infected with $1 \times 10^{6} \mathrm{C}$. albicans/mouse on day 0 .

Table 1. Effect of ubenimex on Candida albicans infection in immunosuppressed mice. ${ }^{a}$

\begin{tabular}{|c|c|c|c|c|}
\hline \multirow{2}{*}{\multicolumn{2}{|c|}{ Treated with ${ }^{b}$}} & \multirow{2}{*}{$\begin{array}{l}\text { Survival } \\
\text { on day } 14 \\
\text { post- } \\
\text { infection }\end{array}$} & \multicolumn{2}{|c|}{$\begin{array}{l}\text { Culture study with } \\
\text { surviving mice } \\
\text { recovery of } \\
\text { C. albicans from; }\end{array}$} \\
\hline & & & $\begin{array}{c}\text { Both } \\
\text { kidneys }\end{array}$ & $\begin{array}{c}\text { One } \\
\text { kidney }\end{array}$ \\
\hline Saline & & $0 / 7$ & - & - \\
\hline \multirow[t]{3}{*}{ Ubenimex } & $0.5 \mathrm{mg} / \mathrm{kg}$ & $4 / 7^{d}$ & $2 / 4$ & $2 / 4$ \\
\hline & $5 \mathrm{mg} / \mathrm{kg}$ & $4 / 6^{d}$ & $3 / 4$ & $1 / 4$ \\
\hline & $25 \mathrm{mg} / \mathrm{kg}$ & $1 / 7$ & $1 / 1$ & $0 / 1$ \\
\hline
\end{tabular}

a Female CD1 mice (4 weeks, 7 animais/dose, except for 6 animals $5 \mathrm{mg} / \mathrm{kg}$ of ubenimex) were iv infected with $5 \times 10^{4} \mathrm{C}$. albicans/mouse on day 0 . Cyclophosphamide $(200 \mathrm{mg} / \mathrm{kg})$ was injected ip on day -4 .

b Saline or ubenimex was ip administered on day -5 to -1 .

c Recovery of $C$. albicans from each kidney of the survivors was examined on day 14.

d $P<0.05$, by Fisher exact test.

\section{Effect on Intraperitoneal Exudation of}

Neutrophils and Other Cells and Their Functions

The total number of PEC and the number of neutrophils in PEC were examined following
Fig. 2. Increment by ubenimex of number of caseininduced neutrophils in the peritoneal cavity of normal mice.

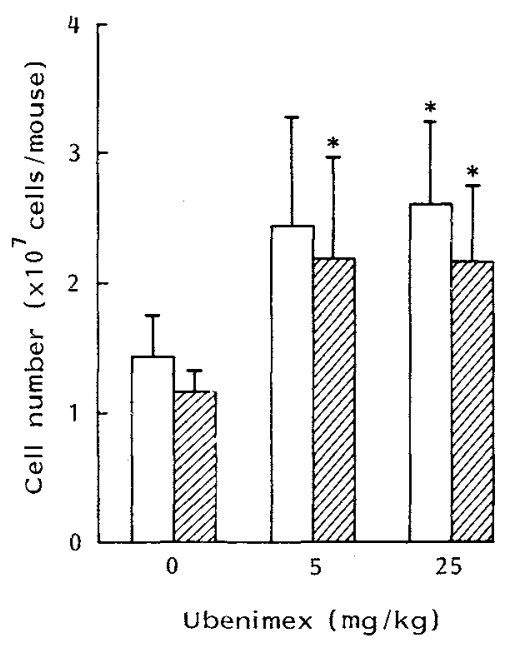

$\mathrm{C} 3 \mathrm{H} / \mathrm{HeN}$ mice were administered ubenimex on day -4 to day $-1(n=5)$. The number of casein-induced PEC (open) and the number of neutrophils in PEC (closed) were determined on day 0 .

$* P<0.05$, against saline-treated group by STUDENT's $t$-test. ubenimex administration in mice with or without casein induction. In the absence of casein induction, the total number of PEC was about $5 \times 10^{6} \mathrm{cells} /$ mouse and the proportion of neutrophils to whole PEC was about $17 \%$ in the saline-treated group. Ubenimex treatment of mice did not change these values. 
Table 2. Phagocytic activity of neutrophils from ubenimex-pretreated normal mice.

\begin{tabular}{|c|c|c|}
\hline \multirow{2}{*}{$\begin{array}{l}\text { Neutrophils from mice } \\
\text { treated with }\end{array}$} & \multicolumn{2}{|c|}{$\begin{array}{c}\% \text { of } C \text {. albicans-phagocytizing } \\
\text { neutrophils }\end{array}$} \\
\hline & Mean $\pm S D$ & Index ${ }^{c}$ \\
\hline Saline & $18.9 \pm 3.2$ & 100 \\
\hline Ubenimex $25 \mathrm{mg} / \mathrm{kg}$ & $28.0 \pm 7.5^{\mathrm{d}}$ & 148 \\
\hline \multicolumn{3}{|c|}{$\begin{array}{l}\mathrm{C} 3 \mathrm{H} / \mathrm{HeN} \text { mice were administered saline or ubenimex } \\
\text { daily for } 4 \text { days }(n=6) \text {. }\end{array}$} \\
\hline \multicolumn{3}{|c|}{$\begin{array}{l}\text { Formaline-killed } C \text { albicans }\left(2 \times 10^{7} \text { cells }\right) \text { and } \\
\text { neutrophils }\left(4 \times 10^{6} \text { cells }\right) \text { were incubated, and } \\
\text { phagocytosis was determined by trypan blue and } \\
\text { eosin Y staining. }\end{array}$} \\
\hline \multicolumn{3}{|c|}{$\begin{array}{l}\text { Relative value of } C \text {. albicans-phagocytizing neutro- } \\
\text { phils to control. }\end{array}$} \\
\hline d $P<0.05$, by STUde & ENT's $t$-test. & \\
\hline
\end{tabular}

Table 3. Enhancement by ubenimex of chemiluminescence response of $\mathrm{PEC}$ from cyclophosphamidetreated mice. ${ }^{\mathrm{a}}$

\begin{tabular}{lccc}
\hline \multirow{2}{*}{$\begin{array}{c}\text { Neutrophils from mice } \\
\text { treated with }\end{array}$} & \multicolumn{2}{c}{ Counts per minute $^{\mathrm{c}}$} \\
\cline { 2 - 4 } & Mean $\pm \mathrm{SD}$ & Index $^{\mathrm{d}}$ \\
\hline Saline & & $2,053 \pm 223$ & 100 \\
Ubenimex & $0.5 \mathrm{mg} / \mathrm{kg}$ & $2,544 \pm 476$ & 124 \\
& $5 \mathrm{mg} / \mathrm{kg}$ & $3,026 \pm 328^{\mathrm{e}}$ & 147 \\
& $25 \mathrm{mg} / \mathrm{kg}$ & $3,059 \pm 77^{\mathrm{f}}$ & 149 \\
\hline
\end{tabular}

a $\mathrm{C} 3 \mathrm{H} / \mathrm{HeN}$ mice were given cyclophosphamide $(200 \mathrm{mg} / \mathrm{kg}$, ip) on day -4 .

b Mice were administered saline or ubenimex ip on day -4 to day $-1(n=3)$.

c Chemiluminescence was measured as described in Materials and Methods.

d Relative value of chemiluminescence response to control.

e $P<0.05$, by STUDENT's $t$-test.

f $P<0.01$, by STUDENT's $t$-test.
Fig. 3. Effects of ubenimex on the number of neutrophils in the peritoneal cavity of cyclophosphamide-treated mice.

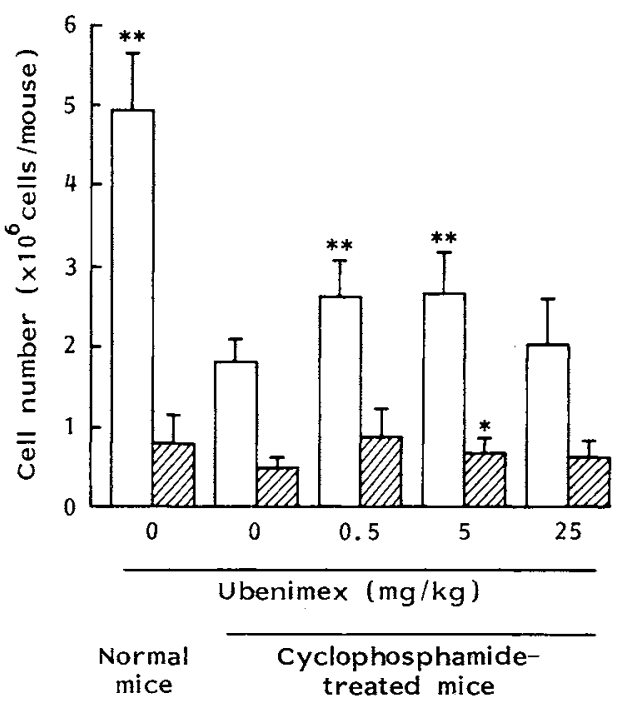

$\mathrm{C} 3 \mathrm{H} / \mathrm{HeN}$ mice were given cyclophosphamide $(200 \mathrm{mg} / \mathrm{kg}$, ip) on day -4 and ubenimex was administered on day -4 to day -1 ( $n=9$ for saline group and $5 \mathrm{mg} / \mathrm{kg}$, and $n=4$ for group of $0.5 \mathrm{mg} / \mathrm{kg}$ and $25 \mathrm{mg} / \mathrm{kg}$ ). The number of PEC (open) and the number of neutrophils in PEC (closed) were determined on day 0 .

${ }^{*} P<0.05,{ }^{*} P<0.01$ against cyclophosphamidesaline-treated group by STUDENT's $t$-test

In casein-induced mice, both the number of PEC and the proportion of neutrophils significantly increased compared with the values for non-induced mice. Ubenimex treatment enhanced the effect of casein induction (Fig. 2). To study whether or not ubenimex augments the function of neutrophils, the

effect on phagocytosis of $C$. albicans by neutrophils was also investigated. As shown in Table 2, ubenimex significantly increased the number of phagocytizing neutrophils. With some other functions of neutrophils, such as production of active oxygen and adhesion to a plastic surface, no statistically significant difference was observed between the ubenimex-untreated and -treated groups of normal mice (data not shown).

Fig. 3 shows the result of experiments on the effect of ubenimex on neutrophil recovery following treatment with an immunosuppressive dose of cyclophosphamide. The total number of PEC and the number of neutrophils were determined without casein induction in ubenimex-treated mice. Cyclophosphamide reduced the total number of PEC to $1.80 \times 10^{6}$ cells/mouse. Under this experimental condition, ubenimex treatment significantly diminished the reduction $\left(2.65 \times 10^{6} \mathrm{cells} / \mathrm{mouse}\right)$. The number of neutrophils in the PEC of ubenimex $(5 \mathrm{mg} / \mathrm{kg})$-treated mice was also slightly but significantly larger than cyclophos- 
phamide-treated control. Investigations of the ability of active oxygen production by PEC following cyclophosphamide treatment (Table 3) revealed that ubenimex treatment at doses of 5 and $25 \mathrm{mg} / \mathrm{kg}$ significantly enhanced active oxygen production by PEC obtained from cyclophosphamide-treated mice. These results indicate that the administration of ubenimex is effective not only in increasing the number of PEC but also in activating their functions.

\section{Discussion}

We demonstrated that ubenimex enhanced host resistance against $C$. albicans infection in both normal and immunosuppressed mice. To our knowledge this is the first report that ubenimex has protective activity against fungal infection in vivo. In normal mice ubenimex showed dose-dependent efficacy, namely, $25 \mathrm{mg} / \mathrm{kg}$ was more beneficial than $5 \mathrm{mg} / \mathrm{kg}$. However, in immunosuppressed mice ubenimex was more effective at the lower dose of $5 \mathrm{mg} / \mathrm{kg}$. These results correspond to the effects of ubenimex on the number of neutrophils in the peritoneal cavity (Figs. 2 and 3). It is well known that neutrophils, along with macrophages, are one of the major defensive factors against Candida infection. Preclinical data has revealed that ubenimex is a potent macrophage-augmenting agent causing increased release of interleukin- 1 and lysosomal enzymes $^{16)}$. Ubenimex augments macrophage tumoricidal activity and has the ability to increase mixed lymphocyte response. However, its effect on neutrophil functions had not been previously clarified in mice. The results of the present study showed that ubenimex induced an enhancement of phagocytosis and production of active oxygen by neutrophils. In addition, it caused a significant increase in the number of neutrophils exudated into the peritoneal cavity in mice. The protective action of this microbial metabolite against candidasis is thus probably due to its stimulating effects on neutrophils. We have recently reported that treatment of immunosuppressed mice with ubenimex increases the frequency and absolute numbers of colony forming unit granulocyte macrophages (CFU-GM), resulting in an increase in the number of nucleated bone marrow cells and white blood cells ${ }^{17}$. In human, JARSTRAND et al. demonstrated that oral administration of ubenimex potentiated phagocytic activity of granulocytes ${ }^{18)}$. Suss et al . reported that ubenimex in vitro stimulated the phagocytic activity of human leucocytes against Saccharomyces cervisiae ${ }^{19)}$. These results strongly support that ubenimex stimulates granulocytes both in mice and humans.

Ubenimex is a potent inhibitor of leucine aminopeptidase and aminopeptidase B. Look et al. reported that aminopeptidase $\mathrm{N}$ is identical to human myeloid plasma membrane glycoprotein $\mathrm{CD} 13$ (gp 150$)^{20)}$. The possible interaction of ubenimex with CD13 might be involved in neutrophil activation.

Recently CHEN et al. have reported that BRMs including lipopolysaccharide (LPS), lentinan and levamisole can prolong survival time of mice experimentally infected with a lethal dose of C. albicans ${ }^{21)}$. Ubenimex might have a greater advantage to control fungal infections in immunosuppressed hosts including those with chronic leukemia or receiving intensive cancer chemotherapy because of its lower toxicity.

\section{References}

1) Umezawa, H.; T. Aoyagi, H. Suda, M. Hamada \& T. Takeuchi: Bestatin, an inhibitor of aminopeptidase B, produced by actinomycetes. J. Antibiotics 29: 97 99, 1976

2) Talmadge, J. E; M. Koyama, A. Matsuda, C. Long \& F. Abe: Immunotherapeutic properties of bestatin: Mechanism of activity. In Recent Results of Bestatin 1986. Ed., H. UmeZAwa, pp. 8 25, Japan Antibiotics Res. Assoc., Tokyo, 1986

3) Aвe, F.; A. Fuji, K. Yoshimura, E. Yugeta, M. Ishizuka \& T. Takeuchi: Immunomodulatory and therapeutic characteristics of bestatin (ubenimex). Int. J. Immunotherapy 6: $203 \sim 209,1990$

4) Koyama, M.: Pharmacokinetics and biotransformation of bestatin. In Recent Results of bestatin 1986. Ed., H. Umezawa, pp. $41 \sim 50$, Japan Antibiotics Res. Assoc., Tokyo, 1986

5) Yamashita, T.; J. Ito, F. Abe, K. Takahashi, T. Takeuchi \& M. Enomoto: Autoradiographic study of tissue distribution of $\left[{ }^{3} \mathrm{H}\right]$-ubenimex in IMC carcinoma-bearing mice. Int. J. Immunopharmacol. 12: 755 760, 1990

6) Müller, W. E. G.; D. K. Schuster, R. K. Zahn, A. Maidhof, G. Leyhausen, D. Falke, R. Koren \& H. UMEZAWA: Properties and specificity of binding sites for the immunomodulator bestatin on the surface of mammalian cells. Int. J. Immunopharmacol. 4: $393 \sim 400,1982$ 
7) Ota, K.; S. Kurita, K. Yamada, T. Masaoka, Y. Uzuka \& N. OGaWa: Immunotherapy with bestatin for acute nonlymphocytic leukemia in adults. Cancer Immunol. Immunother. 23: 5 10, 1986

8) Harada, Y.; A. Kajiki, K. Higuchi, T. Ishibashi \& M. Takemoto: The mode of immunopotentiating action of bestatin.: Enhanced resistance to Listeria monocytogenes infection. J. Antibiotics 36: $1411 \sim 1414,1983$

9) Dickneite, G.; F. Kaspereit \& H. H. Sedlacek: Stimulation of cell-mediated immunity by bestatin correlates with reduction of bacterial persistence in experimental chronic Salmonella typhimurium infection. Infect. Immun. 44: $168 \sim 174,1984$

10) Tanaka, N.; Y. Kumamoto, T. Hirose \& A. Yokoo: Study of the prophylactic effect of ubenimex on experimental pyelonephritis induced by Pseudomonas aeruginosa in neutropenic mice. J. Jpn. Assoc. Infec. Diseases 63: 748 756, 1989

11) KNoblich, A; W. E. G. Müller, V. HARle-Grupp \& D. Falke: Enhancement of antibody formation against Herpes simplex virus in mice by the T cell mitogen bestatin. J. Gen. Virol. 65: 1675 1686, 1984

12) Mathé, G.; H. Umezawa, L. Misset, S. Brienza, C. Canon, M. Musset \& P. Reizenstein: Immunomodulating properties of bestatin in cancer patients, a phase II trial. Biomed. Pharmacother. 40: 379 382, 1986

13) Morikawa, K.; S. Kamegaya, M. Yamazaki \& D. Mizuno: Hydrogen peroxide as a tumoricidal mediator of murine polymorphonuclear leukocytes induced by a linear $\beta$-1,3-D-glucan and some other immunomodulators. Cancer Res. 45: 3482 3486, 1985

14) Lehrer, R. I.; L. G. Ferrari, J. P-Delafield \& T. Sorrell: Fungicidal activity of rabbit alveolar and peritoneal macrophages against Candida albicans. Infect. Immun. 28: $1001 \sim 1008,1980$

15) Allen, R. C. \& L. D. Loose: Phagocytic activation of a luminol-dependent chemiluminescence in rabbit alveolar and peritoneal macrophages. Biochem. Biophys. Res. Comm. 69: 245 252, 1976

16) Shibuya, K. E. Hayashi, F. Abe, K. TaKahashi, H. Horinishi, M. Ishizuka, T. Takeuchi \& H. Umezawa: Enhancement of interleukin 1 and interleukin 2 releases by ubenimex. J. Antibiotics 40: 363 369, 1987

17) ABe, F.; A. Matsuda, M. SChNEIDER \& J. E. TALMADGE: Effects of bestatin on myelopoietic stem cell in normal and cyclophosphamide treated mice. Cancer Immunol. Immunother. 32: 75 80, 1990

18) JARSTRAND, C. \& H. BLOMGREN: Increased granulocyte phagocytosis after oral administration of bestatin, a new immunomodulator. J. Clin. Lab. Immunol. 7: 115 118, 1982

19) Suss, J.; R. Egerer \& A. Stelzner: A phagocytosis capacity assay: Parallel measurement of the phagocytosis and the intracellular killing in granulocytes and the influence of some substances on these processes. Zbl. Bakt. 275: $248 \sim 255,1991$

20) Look, A. T.; R. A. Ashmum, L. H. Shapiro \& S. C. Peiper: Human myeloid plasma membrane glycoprotein CD13 (gp150) is identical to aminopeptidase N. J. Clin. Invest. 83: 1299 1307, 1989

21) Chen, H. Y.; S. Kaneda, Y. MiKami, T. Arai \& K. IGarashi: Protective effects of various BRMs against Candida albicans infection in mice. Jpn. J. Med. Mycol. 28: 306 315, 1987 